\title{
Trends in Extreme Precipitation Indices in Iran: 1951-2007
}

\author{
Robert C. Balling Jr., ${ }^{1}$ Mohammad Sadegh Keikhosravi Kiany, ${ }^{2}$ \\ Shouraseni Sen Roy, ${ }^{3}$ and Javad Khoshhal ${ }^{2}$ \\ ${ }^{1}$ School of Geographical Sciences and Urban Planning, Arizona State University, Tempe, AZ 85287, USA \\ ${ }^{2}$ Faculty of Geographical Sciences and Planning, University of Isfahan, Isfahan, Iran \\ ${ }^{3}$ Department of Geography and Regional Studies, University of Miami, Coral Gables, FL 33146, USA
}

Correspondence should be addressed to Robert C. Balling Jr.; robert.balling@asu.edu

Received 1 October 2015; Revised 13 December 2015; Accepted 14 January 2016

Academic Editor: Roberto Fraile

Copyright (C) 2016 Robert C. Balling Jr. et al. This is an open access article distributed under the Creative Commons Attribution License, which permits unrestricted use, distribution, and reproduction in any medium, provided the original work is properly cited.

\begin{abstract}
We investigate trends in extreme precipitation in Iran for 1951-2007 using the recently released APHRODITE daily rainfall time series. We find that seven different indices of extreme precipitation all show an upward trend through the study period. The seven different precipitation indices include annual precipitation total, number of days above a certain threshold, maximum precipitation received over a certain period of time, maximum one-day precipitation, and number of days with precipitation above the 90 th percentile. A principal components analysis reveals one eigenvector explaining much of the variance in the seven indices and reveals that this component exhibits a strong upward trend for the whole of Iran. On a regional level, we find that the upward trend in extreme precipitation has a strong southwest-to-northeast gradient across the country for all the indices. We repeated all the analyses for 42 stations across the country to compare with the results from the gridded data; trends in extreme rainfall generated from the station data compare favorably with the results from the APHRODITE daily rainfall time series thereby reinforcing the robustness of our conclusions.
\end{abstract}

\section{Introduction}

An extreme event is generally defined as the occurrence of a weather or climate event above or below a threshold value near the upper or lower ends of the range of observed values for a specific variable. Some of the main findings from the latest report on climate change and a special report on extreme events from the Intergovernmental Panel on Climate Change indicate a greater consensus within scientific literature about a likely increase in the frequency and intensity of heavy precipitation events over land areas since 1950, with a likely increase in the frequency of heavy precipitation or proportion of heavy precipitation in the 21st century. Additionally, there is medium confidence about the anthropogenic influence on the intensification of extreme precipitation on the global scale $[1,2]$. In a comprehensive study examining the spatial patterns of precipitation extremes, Alexander et al. [3] reported a significant increase in precipitation extremes, with less spatially coherent patterns compared with trends in extreme temperatures. In view of the widespread impacts of the extreme events on human, ecological, and/or physical systems, there is increased focus on the long-term trends of such events across the globe. The majority of studies based on observational data indicate a general increase in extreme heavy precipitation events, which is attributed to anthropogenic forcing caused by increased levels of moisture in the atmosphere and warmer temperatures overall [4].

Indeed, enhanced levels of water vapor due to warmer oceans in the lower latitudes were found by Trenberth et al. [5]. This has been further confirmed by increasing trends in specific humidity at the global level since $1970[6,7]$. Additionally, results from CMIP3 and CMIP5 simulations also show an increase in the globally averaged 20 -year return values of annual maximum 24-hour precipitation amounts at approximately 6 to $7 \%$ for each ${ }^{\circ} \mathrm{C}$ of global average warming $[8,9]$. Several studies have highlighted the significant role of large scale circulation patterns on the positive trends in extreme precipitation events also $[10,11]$. 


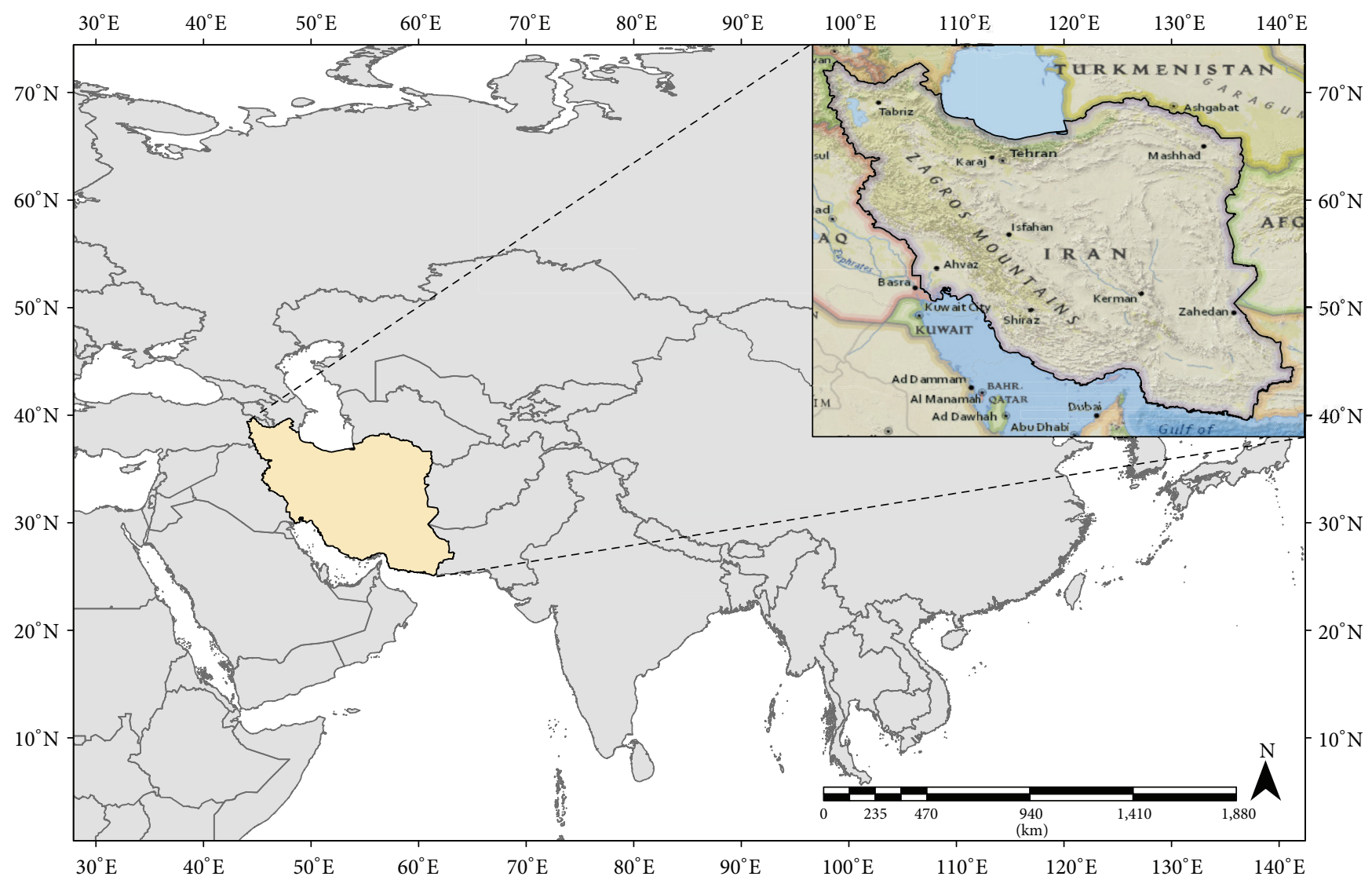

Figure 1: Location of Iran with stylized topographic depiction. Elevation ranges from $-28 \mathrm{~m}$ near the Caspian Sea to $5610 \mathrm{~m}$ atop Mt. Damavand.

There are significant variations in long-term trends in precipitation regionally, with most of the continents, except North America and Europe, showing medium confidence in increasing trends in the frequency and intensity of observed heavy precipitation events [12]. Additionally, the majority of the land areas show an increase in extreme events during the summer season, except Europe which experienced increasing trends during the winter season [12]. Some of the specific regional level studies for extreme precipitation events show likely increases in North America [13-15] and South America $[14,16]$ for the entire 20th century. In the case of Europe and the Mediterranean region, the trends were mixed with most of the increase observed during the winter season and decreasing trends in the summer season precipitation [17-19]. Most of Asia and Oceania experienced mixed trends, with a greater proportion of the region showing a positive trend in extreme precipitation events [20-24]. Additionally, in the case of Africa, there were no clear significant trends [12, 25]. However, on the other hand there are a limited number of studies examining the trends in extreme precipitation patterns in the Middle East, likely due to the lack of longterm data, where Iran, the main focus of this study, is located. One of the few studies includes an analysis of station level precipitation across Iran in which Alijani et al. [26] found more than $20 \%$ of the land area exposed to the risk of extreme rainfall. Specifically the hot, dry southern coast and the western slopes of the main northsouth range, the Zagros Mountains, experienced the most frequent heavy rainfall events. Furthermore, Rahimzadeh et al. [27] examined extreme temperatures and precipitation across 27 synoptic stations across Iran. The results of their analysis indicated marked negative trends in cool days and cool nights, diurnal temperature range (DTR), and positive trends in warm days and tropical nights. Recently, with the advent of gridded data developed from station level measurements at high spatial resolutions, it has become possible to conduct detailed analysis of extreme precipitation events over these regions. Accordingly, in the present study we have analyzed trends in extreme precipitation for Iran which represents a location with precipitation coming largely from cool-season cyclonic events and limited warm-season convective precipitation.

\section{Study Area: Iran}

Iran is located between $25^{\circ}$ and $40^{\circ} \mathrm{N}$ and $45^{\circ}$ and $60^{\circ} \mathrm{E}$ and is a mountainous country bordering the Gulf of Oman, the Persian Gulf, and the Caspian Sea (Figure 1). The total area of Iran is $1.648 \times 10^{6} \mathrm{~km}^{2}$ which represents 0.32 percent of the Earth's surface. Overall, sixty percent of Iran is covered 
by mountains, with the central part of the country consisting of two dry deserts: the Dasht-e-Kavir and the Dasht-e-Lut. The Alborz range in the north, close to the Caspian Sea, extends in an east-west direction with a maximum elevation of approximately $5000 \mathrm{~m}$. The Zagros Mountains are aligned in a northwest-to-southeast direction and reach a maximum elevation of approximately $3500 \mathrm{~m}$. These two ranges play a significant role in determining the nonuniform spatial and temporal distribution of precipitation across the entire country [28]. For instance, the high ranges of the Alborz Mountains in the north and Zagros Mountains in the west inhibit much of the moisture available from adjacent water bodies from reaching the interior of the country. Thus, the interior parts of the country receive much less precipitation. Most of the interior slopes of the Zagros Mountains experience a rain shadow effect with annual rainfall much less than their western counterparts. More than half of the country receives less than $200 \mathrm{~mm}$ of precipitation, with some regions that get less than $50 \mathrm{~mm}$ annually [26].

Over the past decade, important papers have been published focusing on trends in precipitation across Iran (e.g., $[29,30])$. The analysis of station level precipitation data revealed a decreasing trend in annual rainfall at $67 \%$ of the stations, while an increasing trend was observed in the $24 \mathrm{hr}$ maximum rainfall at $50 \%$ of the stations by Modarres and Sarhadi [29]. Recently, Tabari and Talaee [31] studied temporal trends in the annual rainfall time series in the west, south, and southwest of Iran during 1966-2005. The results revealed no visible rainfall trends in the region for their study period. Soltani et al. [32] investigated annual and monthly trends in rainfall amount, number of rainy days, and maximum rainfall in $24 \mathrm{~h}$ based on the data collected at 33 synoptic stations in Iran. The results indicated that there are no significant linear trends in monthly rainfall at most of the synoptic stations. Some'e et al. [33] investigated the spatiotemporal trends and variability of precipitation data from 28 synoptic stations in Iran on the annual and seasonal timescales for the period 1967-2006. Their results revealed negative trends in annual precipitation at 22 sites (79\%), but only three sites had a statistically significant negative trend in precipitation. However, a subsequent study by Raziei et al. [34] using the gridded APHRODITE dataset found an upward trend in daily annual precipitation in most of Iran. Talaee [35] analyzed the annual, seasonal, and monthly rainfall time series at seven rain gauge stations in Hamadan Province located in the west of Iran for a 40year period (from October 1969 to September 2009). Their results showed no clear rainfall trends for this Province of Iran. Alijani et al. [26] analyzed daily rainfall concentration and intensity over Iran using 90 stations over varying time periods. The results showed that daily precipitation tends to be irregular and intense across much of Iran and that a disproportionately large share of the annual rainfall comes from a small number of high-intensity-to-extreme rainfall events. Using meteorological data from the Urmia synoptic station, Delju et al. [36] analyzed climate variability and change in the Urmia Lake Basin in the northwest of Iran. They found that mean precipitation has decreased by $9.2 \%$ during 1964-2005.

\section{3. “APHRODITE” Dataset}

The Asian Precipitation-Highly Resolved Observational Data Integration towards the Evaluation of Water Resources (APHRODITE) dataset is a long-term daily gridded precipitation dataset for Asia, which is based on a dense network of rain gauges. The spatial resolution of this dataset is $0.5^{\circ}$ latitude by $0.5^{\circ}$ longitude. The data used in the construction of this gridded dataset are from three sources which include GTS-based data (the global summary of the day), data precompiled by other projects or organizations, and APHRODITE's own collection [37]. In this paper the version APHRO_V1101 of APHRODITE was used. In case of Iran station level rain gauge data were provided by the Iran Meteorological Organization. Several quality control measures were conducted on the raw dataset, such as checking for conversion between units of millimeters and inches, discrepancies between two or more databases containing the same measurements, and comparing locations with national boundaries and elevation. Next, the station level data were interpolated using a modified version of the Shepard [38] algorithm, which takes into consideration local elevation differences and horizontal distances. The interpolation technique used in APHRODITE products takes into consideration the ratio of daily precipitation to daily climatology. Further detailed information about the interpolation techniques and additional detailed information about the creation of the APHRODITE dataset are available from Yatagai et al. $[37,39,40]$. This dataset has been successfully used to study different aspects of precipitation patterns in Iran by $[30,41]$. It is important to note that the APHRODITE dataset is limited in its estimation of precipitation for high altitude regions in Asia [42-44]. However, the assessment of this dataset for estimation of precipitation patterns across Iran indicates higher levels of accuracy and efficiency [45]. More specifically, a recent study by Ghajarnia et al. [46], consisting of a comparative evaluation of various gridded datasets over Urmia Basin, Iran, revealed that the APHRODITE dataset was able to detect $75 \%$ of the rainfall events, and $39 \%$ of its rainfall estimations were no rain observations.

\section{Station Precipitation Data}

Daily rainfall data from 42 stations operated by the Meteorological Organization of Iran were used to evaluate extreme rainfall trend throughout the country (Figure 2). These stations were selected because they have the longest daily rainfall records and are fairly evenly spread throughout the country. Quality controls are applied to the data by the meteorological organization before releasing them to the user's community. There are many weather stations in Iran, but we limited our study to only 42 stations that had data for the period from 1970 to 2009. 18 stations were used in this study with no missing data whatsoever. Another 11 stations had less than $1 \%$ of the daily data missing; however, 5 stations had less than $10 \%$ of the daily data missing. Eight stations had more than 10\% of the data missing. We used several methods to address the missing data issue including substituting the missing value with the climatological average for that day and/or simply 


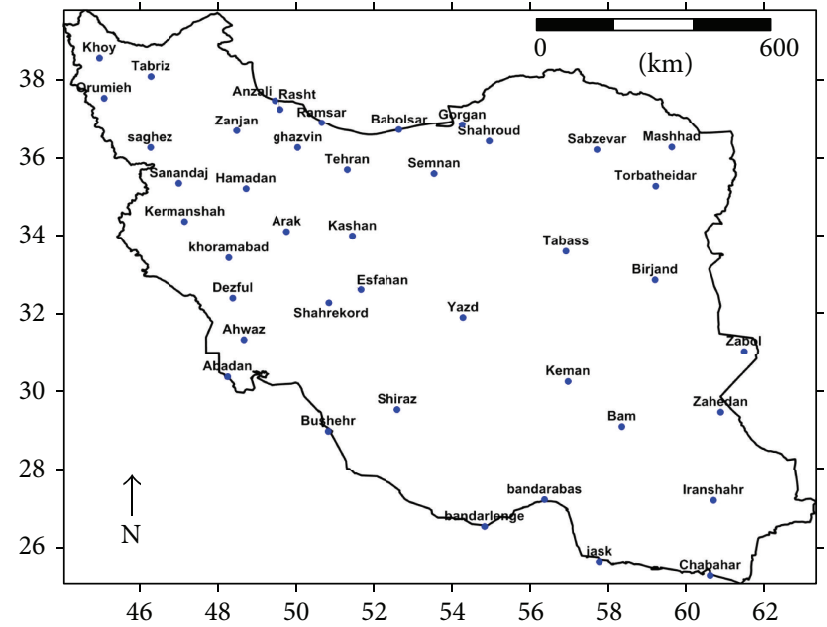

FIGURE 2: Location of 42 meteorological stations in Iran used in this study.

eliminating stations with more than $10 \%$ missing values. Our decisions did not appear to influence the final results in any meaningful way.

\section{Analyses and Results}

As seen in Figure 3, 618 of the $0.5^{\circ} \times 0.5^{\circ}$ grid points in the APHRODITE dataset fall within the political boundary of Iran. Therefore, our initial matrix of daily precipitation consisted of 20818 rows, one for each day from January 1 , 1951, to December 31, 2007, and 618 columns, one for each grid point in Iran. The average monthly precipitation for the entire area is shown in Figure 4. We analyzed seven different popular indices (for a similar analysis, see [22]) of extreme precipitation for each grid point and year including the following:

(1) Annual precipitation total (AnnP).

(2) Number of days with precipitation $\geq 10 \mathrm{~mm}$ (ND10mm).

(3) Percent of annual precipitation from daily events $\geq$ $10 \mathrm{~mm}$ (\%Ann10mm).

(4) Number of days with precipitation $\geq 20 \mathrm{~mm}$ (ND20mm).

(5) Number of days with precipitation $\geq$ the 90th percentile of the distribution (ND90\%).

(6) Maximum precipitation received over five consecutive days (Max5day).

(7) Maximum one-day precipitation (Maxlday).

The calculation of these indices by year and grid point resulted in a new matrix for each index of 57 rows, one for each year from 1951 to 2007, and 618 columns, one for each grid point. In order to compute a countrywide time series for each of the seven indices, the time series at each grid cell was converted to $z$-scores (mean of 0 , standard deviation of 1 ), and the $z$-scores were then averaged across the 618 points.

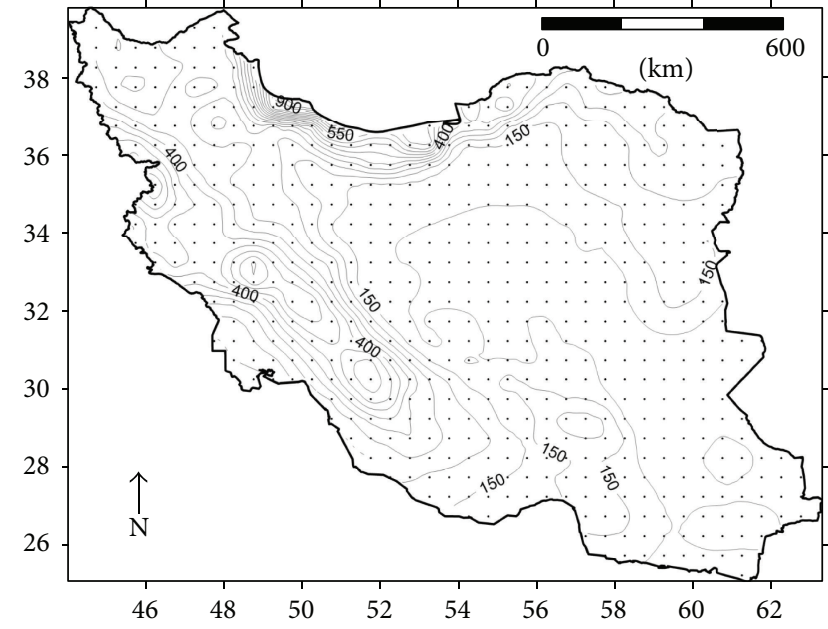

FIGURE 3: Mean annual precipitation (mm) in Iran, 1951-2007, based on 618 grid points throughout the country.

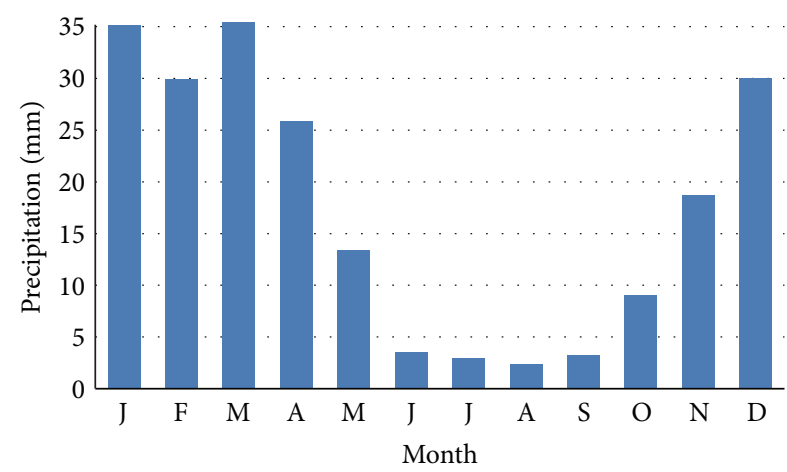

FIgURE 4: Average monthly precipitation $(\mathrm{mm})$ for 618 grid points in Iran, 1951-2007.

This resulted in a final matrix of 57 rows, one for each year, and seven columns, one for each extreme precipitation index. We conducted all analyses with and without an adjustment for leap years and found no meaningful changes in our results.

Recognizing that various statistical techniques used in this study assume normality (a Gaussian distribution) in these time series, we calculated the standardized coefficients of skewness, $z_{1}$, and kurtosis, $z_{2}$, calculated as

$$
z_{1}=\frac{\left[\sum_{i=1}^{N}\left(x_{i}-\bar{X}\right)^{3} / N\right]\left[\sum_{i=1}^{N}\left(x_{i}-\bar{X}\right)^{2} / N\right]^{-3 / 2}}{(6 / N)^{1 / 2}},
$$

$z_{2}$

$$
=\frac{\left\{\left[\sum_{i=1}^{N}\left(x_{i}-\bar{X}\right)^{4} / N\right]\left[\sum_{i=1}^{N}\left(x_{i}-\bar{X}\right)^{2} / N\right]^{-2}\right\}-3}{(24 / N)^{1 / 2}},
$$

where the resulting $z$ values are compared against a $t$-value deemed appropriate for a selected level of confidence (e.g., for $N=57, t=2.66$ for the 0.99 level of confidence). If the absolute value of $z_{1}$ or $z_{2}$ exceeds the selected value 
TABLE 1: Normality test results.

\begin{tabular}{lccc}
\hline Index & $z_{1}$ & $z_{2}$ & K-S \\
\hline AnnP & 0.707 & -1.196 & 0.082 \\
ND10mm & 0.865 & -1.439 & 0.096 \\
\%Ann10mm & 2.510 & 0.338 & 0.132 \\
ND20mm & 2.827 & 0.118 & 0.180 \\
ND90\% & 0.583 & -1.191 & 0.087 \\
Max5day & 1.234 & -0.750 & 0.086 \\
High1day & 2.015 & -0.186 & 0.115 \\
Component 1 & 0.081 & -1.126 & 0.075 \\
\hline
\end{tabular}

$z_{1}$ and $z_{2}$ are standardized indices of skewness and kurtosis; K-S is the Kolmogorov-Smirnov test statistic.

of $t$, a significant deviation from the normal curve is confirmed. Otherwise, no statistically significant deviation from a normal distribution is determined (the null hypothesis that the samples came from a normal distribution cannot be rejected). We also used the Kolmogorov-Smirnov onesample test in which the variable is tested against another variable defined as having a normal distribution. It is similar to a $t$-test determining whether two variables were drawn from different populations. If the Kolmogorov-Smirnov test is statistically significant, we rejected the hypothesis that the observed data follow the normal distribution.

As seen in Table 1 , the only time series with a significant deviation from the normal distribution was the ND20mm index as judged by the Kolmogorov-Smirnov and skewness tests. The deviation was not severe and it could be corrected using a square root transformation in which the sign is maintained and the square root is taken of the absolute value of the $z$-score. All analyses were conducted with and without this transformation and no meaningful differences were observed.

Given the general lack of deviations from normality, we calculated the Pearson product-moment correlation coefficients among the seven time series (Table 2). All intercorrelation coefficients were significant at the $<0.01$ level of confidence and many of the correlation coefficients were above +0.90 . Given the high correlation among the different indices, a principal components analysis (PCA) was conducted to explain the predominant trends in all seven indices analyzed in the present study. The results of PCA to the matrix of seven indices revealed one component explaining $80.9 \%$ of the variance in the matrix. The loadings (Table 3) were all positive and ranged from +0.77 for AnnP to +0.99 for ND10mm. The strength of this one component suggests that it does adequately capture a robust dimension in the precipitation data related to all of the measures of extreme precipitation.

There was no significant deviation from normality in the component scores (Table 1) and as seen in Figure 5, the scores show a distinctive upward trend. Using the year of record as the predictor variable, a simple regression shows that the trend is upward and highly statistically significant $(p<0.01)$ for component 1 and for five of the seven indices; AnnP and ND90\% had upward trends that were not significant at the 0.01 level of confidence.

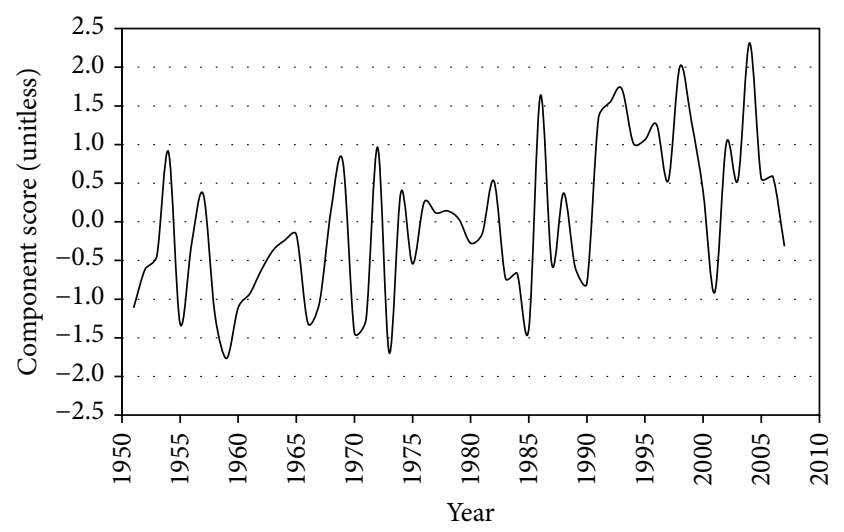

FIGURE 5: Yearly scores for single component explaining $80.9 \%$ of the variance in seven indices of extreme precipitation. Year component scores (standardized, mean of 0 and standard deviation of 1) for the single component explaining $80.9 \%$ of the variance in seven indices of extreme precipitation. The upward trend suggests that extreme precipitation events, irrespective of how they are defined, are increasing in Iran.

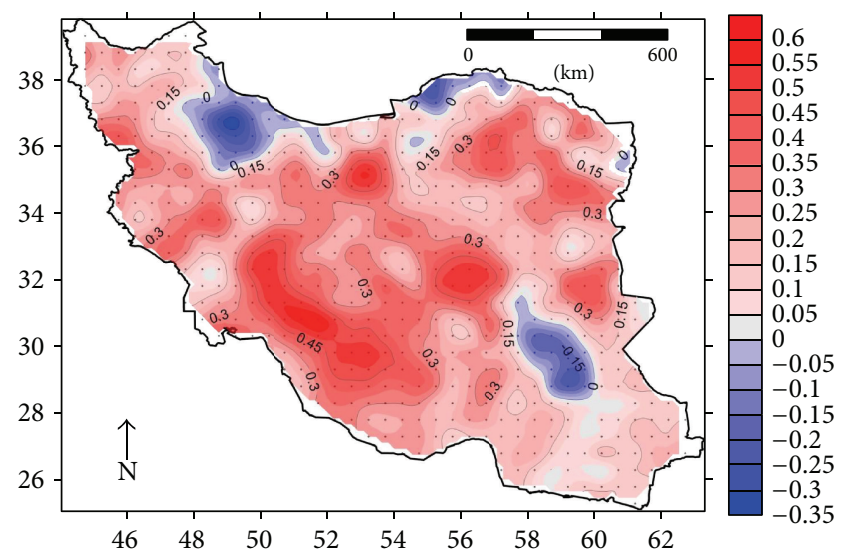

Figure 6: Pearson product-moment correlation coefficients for the relationship between "year" and the number of days with precipitation $\geq 10 \mathrm{~mm}$.

As a final procedure with the APHRODITE dataset, we calculated the linear regression between ND10mm and year of record at each of the 618 grid points and plotted the $r$ values (Figure 6). A strong northeast-to-southwest gradient appeared; a simple first-order polynomial interpolation (basically a plane) explained $83 \%$ of the spatial variance in the data. The lower values were generally concentrated in the northern border of the study area. The more sophisticated universal kriging method, which is useful for estimating local trend, was used to produce the pattern shown in Figure 6 [47]. It explained $95 \%$ of the spatial variance in the correlation coefficient values. Spatial variance explained by an interpolated surface is determined as $1-\left(\mathrm{RMSE}^{2} / \mathrm{SD}^{2}\right)$, where RMSE is the root mean square error of the interpolation and $\mathrm{SD}$ is the standard deviation of the variable being mapped. We repeated the trend analysis using the Mann-Kendall Rank Statistic which also determines the strength, sign, and significance of 
TABLE 2: Pearson product-moment correlation coefficients amount the indices of extreme precipitation.

\begin{tabular}{|c|c|c|c|c|c|c|c|}
\hline Index & AnnP & $\mathrm{ND} 10 \mathrm{~mm}$ & $\%$ Ann10mm & $\mathrm{ND} 20 \mathrm{~mm}$ & ND90\% & Max5day & Highlday \\
\hline AnnP & 1.00 & 0.78 & 0.39 & 0.53 & 0.99 & 0.66 & 0.57 \\
\hline $\mathrm{ND} 10 \mathrm{~mm}$ & & 1.00 & 0.87 & 0.92 & 0.81 & 0.92 & 0.93 \\
\hline$\%$ Ann10mm & & & 1.00 & 0.95 & 0.45 & 0.85 & 0.96 \\
\hline ND20mm & & & & 1.00 & 0.56 & 0.89 & 0.97 \\
\hline ND90\% & & & & & 1.00 & 0.69 & 0.60 \\
\hline Max5day & & & & & & 1.00 & 0.90 \\
\hline Highlday & & & & & & & 1.00 \\
\hline
\end{tabular}

TABle 3: Principal component loadings and trend results for extreme precipitation indices.

\begin{tabular}{lccc}
\hline Index & Loading & $B$ & $r$ \\
\hline AnnP & 0.765 & 1.41 & 0.19 \\
ND10mm & 0.991 & 4.76 & 0.54 \\
\%Ann10mm & 0.885 & 6.06 & 0.63 \\
ND20mm & 0.936 & 5.81 & 0.62 \\
ND90\% & 0.796 & 1.87 & 0.24 \\
Max5day & 0.944 & 4.20 & 0.49 \\
Highlday & 0.952 & 6.16 & 0.64 \\
Component 1 & & 4.82 & 0.54 \\
\hline
\end{tabular}

$B$ values are the standardized regression coefficients (beta weights) and $r$ values are the Pearson product-moment coefficients between the variable and year of record.

trend in the ND10mm variable. As seen in Figure 7, positive and significant trends dominated the central-western and northeastern portions of the country, and in no case was a significant downward trend identified, which is similar to the results found by Raziei et al. [34] and Rahimzadeh et al. [27]. The negative trends were mainly concentrated near the Caspian Sea region in the north and in the south central region, which was similar to the results of Raziei et al. [34]. Previously, Modarres and Sarhadi [29] used a set of 145 rainfall stations in Iran to detect trends in $24 \mathrm{hr}$ maximum rainfall. Consistent with our findings, they reported positive trends in $24 \mathrm{hr}$ maximum rainfall at many of the stations. The increasing trend in heavy rainfall may accelerate soil erosion through flash floods resulting in soil loss in particularly sensitive regions.

We repeated all analyses described above using the daily precipitation data from the 42 stations. We again generated the seven indices for each station and used the $z$-score approach to generate an Iranian-wide time series for each index. Whereas the one principal component explained $80.9 \%$ of the variance in the seven indices based on the APHRODITE data, one component explained $82.0 \%$ of the variance in the seven indices based on the station data. A time series of the component scores had a Pearson productmoment correlation coefficient of 0.69 with the component scores from the APHRODITE analyses. We repeated these analyses based on 34 stations with less than 10\% missing data and found no meaningful differences in the results; the new principal component time series shared a correlation

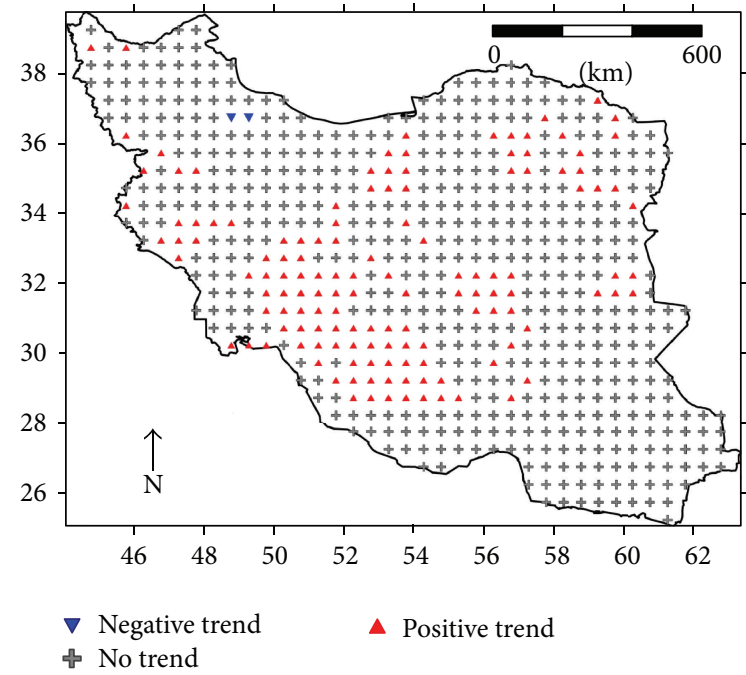

Figure 7: Results from Mann-Kendall Rank Statistic showing the significance of trends $(p=0.01)$ in the number of days with precipitation $\geq 10 \mathrm{~mm}$.

of 0.97 with the time series generated based on all stations. The variations in the trends in the spatial patterns of extreme weather events are mainly driven by orography in the form of the mountains in the northern and western interiors [34].

\section{Conclusions}

We analyzed gridded daily precipitation data from APHRODITE across Iran over the period 1951-2007 and found a strong positive trend in extreme precipitation events. The upward trend appeared in seven different indices and was especially strong in a composite variable of extreme precipitation developed through a principal components analysis. On a regional basis, the trend upward in extreme precipitation was highest in the southwest and least in the northern portions of the country. We found very similar results when we conducted the same analyses based on daily precipitation data from 42 stations across Iran. Our results suggest that the APHRODITE gridded daily precipitation data can appear to be relevant for applications such as trend analysis of extreme events.

Raziei et al. [34] found that precipitation tends to decrease during the warm seasons (spring and summer) and increase 
during cold seasons (autumn and winter) in most of Iran. This would imply less precipitation occurrences during the warm season and an intensification of the seasonality and dryness over the country. Iran usually receives the largest proportion of its rainfall during cold seasons. The findings of the present study indicate a significant upward trend has occurred in extreme indices in southwest of Iran (meaning that the portion of extreme occurrences that contributed to the annual rainfall has increased significantly) along the Zagros Mountains where the most important and the biggest rivers of this region originate (e.g., Karoon River, Dez River). Other parts of the country including the southeast and northwest regions showed no trend over our study period. Increases in both intensification of the seasonality and dryness over Iran, along with the increase in extreme indices of rainfall, would be very hazardous for water availability in an arid region like Iran, which receives only $250 \mathrm{~mm}$ annually. Consistent with our findings, Alijani et al. [26] indicated that days with rain totals above the 90th percentile account for a disproportionate percentage of the nation's total rainfall, and even very rainy areas are at risk of extreme rainfall and associated hazards. Our results, along with the findings of many other studies, suggest that water access will continue to be a challenge in Iran moving forward.

\section{Conflict of Interests}

The authors declare that there is no conflict of interests regarding the publication of this paper.

\section{References}

[1] S. I. Seneviratne, N. Nicholls, D. Easterling et al., "Changes in climate extremes and their impacts on the natural physical environment," in Managing the Risks of Extreme Events and Disasters to Advance Climate Change Adaptation. A Special Report of Working Groups I and II of the Intergovernmental Panel on Climate Change (IPCC), C. B. Field, V. Barros, T. F. Stocker et al., Eds., pp. 109-230, Cambridge University Press, Cambridge, UK, 2012.

[2] IPCC, "Summary for policymakers," in Climate Change 2013: The Physical Science Basis. Contribution of Working Group I to the Fifth Assessment Report of the Intergovernmental Panel on Climate Change, T. F. Stocker, D. Qin, G.-K. Plattner et al., Eds., pp. 3-29, Cambridge University Press, Cambridge, UK, 2013.

[3] L. V. Alexander, X. Zhang, T. C. Peterson et al., "Global observed changes in daily climate extremes of temperature and precipitation," Journal of Geophysical Research: Atmospheres, vol. 111, no. 5, Article ID D05109, 2006.

[4] N. L. Bindoff, P. A. Stott, K. M. Achuta Rao et al., "Detection and attribution of climate change: from global to regional," in Climate Change 2013: The Physical Science Basis. Contribution of Working Group I to the Fifth Assessment Report of the Intergovernmental Panel on Climate Change, T. F. Stocker, D. Qin, G.-K. Plattner et al., Eds., pp. 867-952, Cambridge University Press, Cambridge, UK, 2013.

[5] K. E. Trenberth, P. D. Jones, P. Ambenje et al., "Observations: surface and atmospheric climate change," in Climate Change 2007: The Physical Science Basis. Contribution of Working Group I to the Fourth Assessment Report of the Intergovernmental Panel on Climate Change, S. Solomon, D. Qin, M. Manning et al., Eds., Cambridge University Press, Cambridge, UK, 2007.

[6] A. Dai, "Recent climatology, variability, and trends in global surface humidity," Journal of Climate, vol. 19, no. 15, pp. 35893606, 2006.

[7] K. M. Willett, P. D. Jones, N. P. Gillett, and P. W. Thorne, "Recent changes in surface humidity: development of the HadCRUH dataset," Journal of Climate, vol. 21, no. 20, pp. 5364-5383, 2008.

[8] V. V. Kharin, F. W. Zwiers, X. Zhang, and G. C. Hegerl, "Changes in temperature and precipitation extremes in the IPCC ensemble of global coupled model simulations," Journal of Climate, vol. 20, no. 8, pp. 1419-1444, 2007.

[9] V. V. Kharin, F. W. Zwiers, X. Zhang, and M. Wehner, "Changes in temperature and precipitation extremes in the CMIP5 ensemble," Climatic Change, vol. 119, no. 2, pp. 345-357, 2013.

[10] L. V. Alexander, P. Uotila, and N. Nicholls, "Influence of sea surface temperature variability on global temperature and precipitation extremes," Journal of Geophysical Research: Atmospheres, vol. 114, no. 18, Article ID D18116, 2009.

[11] J. Kenyon and G. C. Hegerl, "Influence of modes of climate variability on global temperature extremes," Journal of Climate, vol. 21, pp. 3872-3889, 2010.

[12] D. L. Hartmann, A. M. G. Klein Tank, M. Rusticucci et al., "Observations: atmosphere and surface," in Climate Change 2013: The Physical Science Basis. Contribution of Working Group I to the Fifth Assessment Report of the Intergovernmental Panel on Climate Change, T. F. Stocker, D. Qin, G.-K. Plattner et al., Eds., pp. 160-254, Cambridge University Press, Cambridge, UK, 2013.

[13] S. C. Pryor, J. A. Howe, and K. E. Kunkel, "How spatially coherent and statistically robust are temporal changes in extreme precipitation in the contiguous USA?" International Journal of Climatology, vol. 29, no. 1, pp. 31-45, 2009.

[14] M. G. Donat, L. V. Alexander, H. Yang et al., "Updated analyses of temperature and precipitation extreme indices since the beginning of the twentieth century: the HadEX2 dataset," Journal of Geophysical Research, vol. 118, no. 5, pp. 2098-2118, 2013.

[15] G. Villarini and G. A. Vecchi, "Twenty-first-century projections of North Atlantic tropical storms from CMIP5 models," Nature Climate Change, vol. 2, no. 8, pp. 604-607, 2012.

[16] M. M. Skansi, M. Brunet, J. Sigró et al., "Warming and wetting signals emerging from analysis of changes in climate extreme indices over South America," Global Planetary Change, vol. 100, pp. 295-307, 2013.

[17] V. Pavan, R. Tomozeiu, C. Cacciamani, and M. di Lorenzo, "Daily precipitation observations over Emilia-Romagna: mean values and extremes," International Journal of Climatology, vol. 28, no. 15, pp. 2065-2079, 2008.

[18] E. Lupikasza, "Spatial and temporal variability of extreme precipitation in Poland in the period 1951-2006," International Journal of Climatology, vol. 30, no. 7, pp. 991-1007, 2010.

[19] A. Toreti, E. Xoplaki, D. Maraun, F. G. Kuglitsch, H. Wanner, and J. Luterbacher, "Characterisation of extreme winter precipitation in mediterranean coastal sites and associated anomalous atmospheric circulation patterns," Natural Hazards and Earth System Science, vol. 10, no. 5, pp. 1037-1050, 2010.

[20] B. N. Goswami, V. Venugopal, D. Sangupta, M. S. Madhusoodanan, and P. K. Xavier, "Increasing trend of extreme rain events over India in a warming environment," Science, vol. 314, no. 5804, pp. 1442-1445, 2006. 
[21] N. Plummer, M. J. Salinger, N. Nicholls et al., "Changes in climate extremes over the Australian region and New Zealand during the twentieth century," Climatic Change, vol. 42, no. 1, pp. 183-202, 1999.

[22] S. S. Roy and R. C. Balling Jr., "Trends in extreme daily precipitation indices in India," International Journal of Climatology, vol. 24, no. 4, pp. 457-466, 2004.

[23] S. S. Roy, "A spatial analysis of extreme hourly precipitation patterns in India," International Journal of Climatology, vol. 29, no. 3, pp. 345-355, 2009.

[24] Y. Wang and L. Zhou, "Observed trends in extreme precipitation events in China during 1961-2001 and the associated changes in large-scale circulation," Geophysical Research Letters, vol. 32, no. 17, Article ID L09707, pp. 1-4, 2005.

[25] S. Sen Roy and M. Rouault, "Spatial patterns of seasonal scale extreme hourly precipitation in South Africa," Applied Geography, vol. 39, pp. 151-157, 2013.

[26] B. Alijani, J. O’Brien, and B. Yarnal, "Spatial analysis of precipitation intensity and concentration in Iran," Theoretical and Applied Climatology, vol. 94, no. 1-2, pp. 107-124, 2008.

[27] F. Rahimzadeh, A. Asgari, and E. Fattahi, "Variability of extreme temperature and precipitation in Iran during recent decades," International Journal of Climatology, vol. 29, no. 3, pp. 329-343, 2009.

[28] S. Javanmard, A. Yatagai, M. I. Nodzu, J. Bodagh Jamali, and H. Kawamoto, "Comparing high-resolution gridded precipitation data with satellite rainfall estimates of TRMM_3B42 over Iran," in Advances in Geosciences, vol. 25, pp. 119-125, 2010.

[29] R. Modarres and A. Sarhadi, "Rainfall trends analysis of Iran in the last half of the twentieth century," Journal of Geophysical Research: Atmospheres, vol. 114, no. 3, Article ID D03101, 2009.

[30] T. Raziei, A. Mofidi, J. A. Santos, and I. Bordi, "Spatial patterns and regimes of daily precipitation in Iran in relation to largescale atmospheric circulation," International Journal of Climatology, vol. 32, no. 8, pp. 1226-1237, 2012.

[31] H. Tabari and P. H. Talaee, "Temporal variability of precipitation over Iran: 1966-2005, Journal of Hydrology, vol. 396, no. 3-4, pp. 313-320, 2011.

[32] S. Soltani, R. Saboohi, and L. Yaghmaei, "Rainfall and rainy days trend in Iran," Climatic Change, vol. 110, no. 1-2, pp. 187-213, 2012.

[33] B. S. Some'e, A. Ezani, and H. Tabari, "Spatiotemporal trends and change point of precipitation in Iran," Atmospheric Research, vol. 113, pp. 1-12, 2012.

[34] T. Raziei, J. Daryabari, I. Bordi, and L. S. Pereira, "Spatial patterns and temporal trends of precipitation in Iran," Theoretical and Applied Climatology, vol. 115, no. 3-4, pp. 531-540, 2014.

[35] P. H. Talaee, "Iranian rainfall series analysis by means of nonparametric tests," Theoretical and Applied Climatology, vol. 116, no. 3-4, pp. 597-607, 2014.

[36] A. H. Delju, A. Ceylan, E. Piguet, and M. Rebetez, "Observed climate variability and change in Urmia Lake Basin, Iran," Theoretical and Applied Climatology, vol. 111, no. 1-2, pp. 285296, 2013.

[37] A. Yatagai, K. Kamiguchi, O. Arakawa, A. Hamada, N. Yasutomi, and A. Kitoh, "APHRODITE: constructing a long-term daily gridded precipitation dataset for Asia based on a dense network of rain gauges," Bulletin of the American Meteorological Society, vol. 93, no. 9, pp. 1401-1415, 2012.

[38] D. Shepard, "A two-dimensional interpolation function for irregularly-spaced data," in Proceedings of the 23rd ACM
National Conference (ACM '68), pp. 517-524, Brandon/Systems Press, Las Vegas, Nev, USA, August 1968.

[39] A. Yatagai, P. Xie, and P. Alpert, "Development of a daily gridded precipitation data set for the Middle East," Advances in Geosciences, vol. 12, pp. 165-170, 2008.

[40] A. Yatagai, O. Arakawa, K. Kamiguchi, H. Kawamoto, M. I. Nodzu, and A. Hamada, "A 44-year daily gridded precipitation dataset for Asia based on a dense network of rain gauges," Scientific Online Letters on the Atmosphere, vol. 5, no. 1, pp. 137140, 2009.

[41] T. Raziei, I. Bordi, J. A. Santos, and A. Mofidi, "Atmospheric circulation types and winter daily precipitation in Iran," International Journal of Climatology, vol. 33, no. 9, pp. 2232-2246, 2013.

[42] C. Andermann, S. Bonnet, and R. Gloaguen, "Evaluation of precipitation data sets along the Himalayan front," Geochemistry, Geophysics, Geosystems, vol. 12, no. 7, Article ID Q07023, 2011.

[43] A. M. El Kenawy and M. F. McCabe, "A multi-decadal assessment of the performance of gauge- and model-based rainfall products over Saudi Arabia: climatology, anomalies and trends," International Journal of Climatology, 2015.

[44] H. Yin, M. G. Donat, L. V. Alexander, and Y. Sun, "Multi-dataset comparison of gridded observed temperature and precipitation extremes over China," International Journal of Climatology, vol. 35, no. 10, pp. 2809-2827, 2015.

[45] E. Nasrabadi, S. A. Masoodian, and H. Asakereh, "Comparison of gridded precipitation time series data in APHRODITE and Asfazari databases within Iran's territory," Atmospheric and Climate Sciences, vol. 3, no. 2, pp. 235-248, 2013.

[46] N. Ghajarnia, A. Liaghat, and P. Daneshkar Arasteh, “Comparison and evaluation of high resolution precipitation estimation products in Urmia Basin-Iran," Atmospheric Research, vol. 158159, pp. 50-65, 2015.

[47] Spatial-analysis.net, Universal Kriging, 2015, http://spatial-analyst.net/ILWIS/htm/ilwisapp/universal_kriging_functionality .htm. 

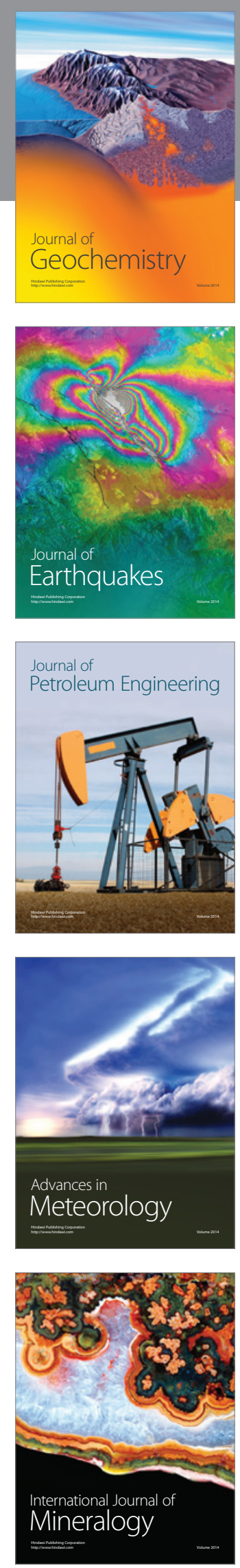
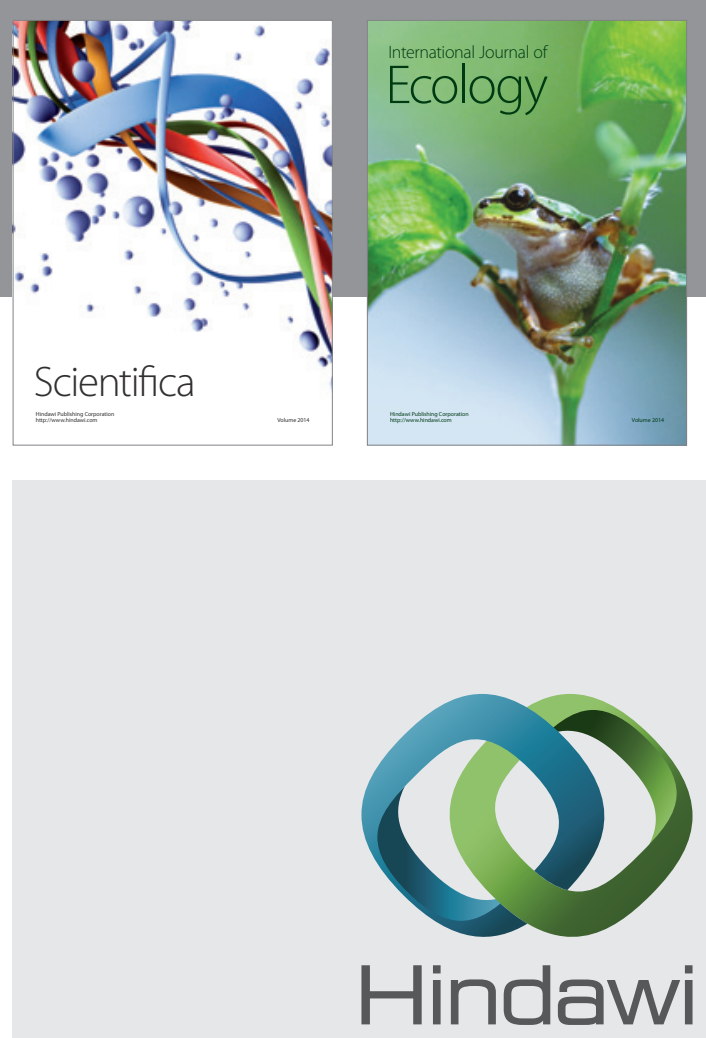

Submit your manuscripts at

http://www.hindawi.com
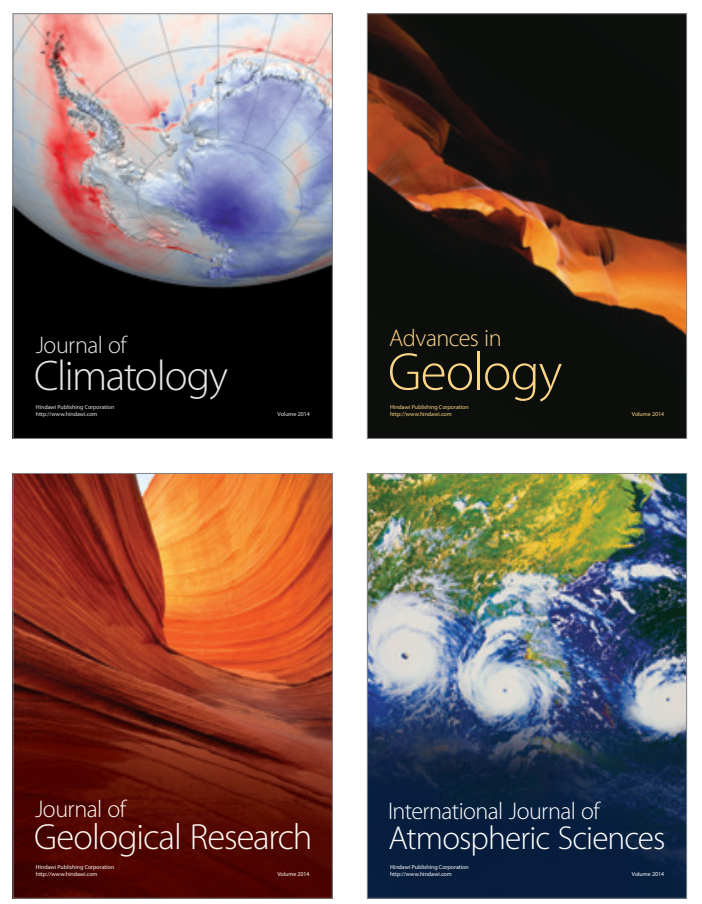

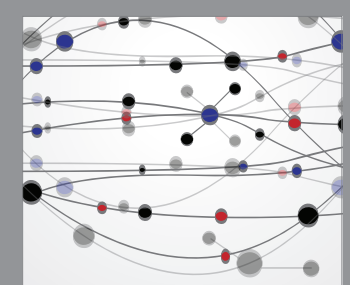

The Scientific

\section{World Journal}
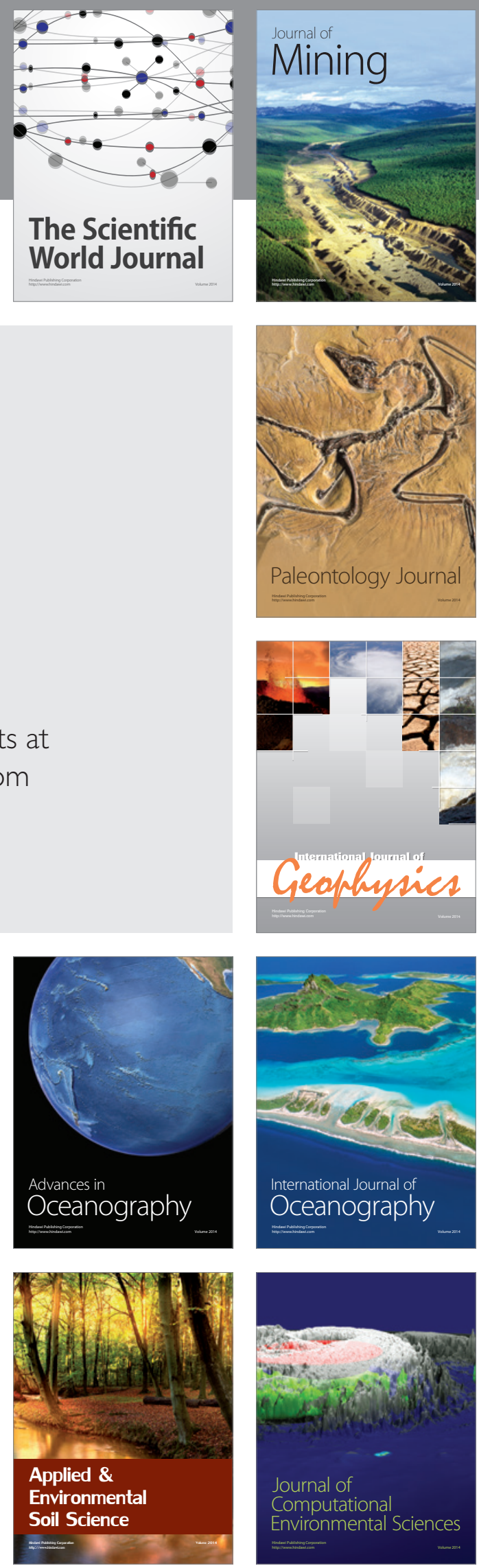